\title{
CORRESPONDENCE
}

\section{Publication Speed}

SiR,-Your recent editorial (Nature, 233, 294 ; 1971) on multiple publication seems to me to put the responsibility of the journals for this practice at a lower value than the facts would merit. You merely suggest that the slowness of the whole process of publication has some effect on the willingness of scientists to "leak" to newspapers before publication. It is, however, quite clear that the frequent lack of efficiency in the processing of articles submitted to learned and technical journals could function as a strong incentive to submission of papers to several journals simultaneously. Old news is no news, in science as elsewhere, and scientists are concerned to have their material appear in print as quickly as possible. If journals appear to reject papers arbitrarily then there is, from the author's viewpoint, something to be gained from a course of action which avoids the possibility of being left six months or even a year behind the field with a perfectly good but homeless paper.

The experience of some members of this laboratory would certainly indicate the need for a certain amount of reform in the way journals are run. I myself am co-author of a paper submitted to a reputable journal in February 1970 which was at first rejected and then, having been refereed again, was accepted in a revised form. This took the remainder of the year although the actual rewriting took perhaps three weeks. This paper has still not appeared, after nearly two years. A second paper for the same journal has been refereed (this took seven months) and has just been rejected by an editorial fiat that the subject matter is not relevant to the journal's interest although the scientific merit is unquestioned. Why could this decision, if justified, not have been made by the editor when he received it? The nature of the subject matter was clear from the title and abstract. An article submitted for the features pages of the journal of an engineering institution was with the editor for three months, at the end of which time he had it set up in type, before he acknowledged receipt of the article. At this point he decided that it was more suitable for the proceedings and scientific papers section of the journal and sub- mitted it to the papers committee of the institution. Another decision which would have been better made at the earliest opportunity.

If editors are willing to countenance in themselves such a lack of regard for the interests of contributors, then they must take the consequences, which may well include multiple publications. Authors should not be expected to sit helpless before this sort of treatment which, in many cases, decreases the value of their work. Editors should acknowledge receipt of papers, reply to authors' letters in less than the month which is common, should as a matter of course prompt referees into faster reading and should make their editorial as distinct from their scientific decisions at an early rather than a late date. They may then find themselves better served by contributors.

$$
\begin{aligned}
& \text { Yours faithfully, } \\
& \text { I. D. GRIFFITHS }
\end{aligned}
$$

The Electricity Council

Research Centre,

Capenhurst,

Chester

\section{Forecasting}

SIR,-In your editorial "How Much is Enough?" (Nature, 234, $115 ;$ 1971) you discuss the difficulty of forecasting population growth, and you ask whether the forecaster-in this case the Government Actuary - should "settle for more modest but more realistic goals". An interesting question, but not confined to the prediction of population.

In any organization concerned with products-schools, hospitals, food supplies, aircraft, weapons-of long gestation, there is always a wish to know the future so that policies can be tailored accurately to meet world conditions as they will exist ten or more years hence. And so there is pressure to forecast not only populations but also social and political attitudes, economic conditions, technological developments and so on.

When these questions are posed, they are answered: "forecasting" has achieved a respectability undreamt of by the seers of the Middle Ages. The forecasts provided become, too often, the single set of assumptions on which planning is based. If the forecast should prove accurate, then the policymakers are labelled "far sighted"; if not, they are, with hindsight, abused for having backed the wrong horse. But might it not be wiser to accept that forecasting is not an exact science. We have the evidence of grossly misleading population predictions; we know that political attitudes can change markedly within a few months; social attitudes appear essentially unpredictable in the longer term; technological forecasts merely reflect an obvious truth that the more money and effort is poured into any project the faster it will move. Against this sort of background, might it not be that the sensible approach is to seek to build a system reasonably matched to a wide range of possible futures rather than closely matched to a single predicted future?

Yours faithfully,

"Woodilee",
Mellersh Hill Road,
Wonersh Park,
Guildford, Surrey

I. J. Shaw

\section{Protecting Potatoes}

SIR,--Under the headline "A Sticky End" (Nature, 233, 93; 1971) your correspondent gave recognition to an interesting piece of work by $\mathrm{Dr} \mathrm{R}$. W. Gibson on the part played by glandular hairs in providing resistance to aphids in three species of pctatoes ( $A n n$. A ppl. Biol., 68, 113; 1971). Gibson showed that glandular hairs on the potato species Solanum berthaultii, S. tarijense, and $S$. polyadenium discharged a gummy exudate which eventually immobilized the aphid and led to its death through starvation. As noted by Gibson this type of mechanism has potential value in the control of aphid population build-up. This effect may be further enhanced if combined with other types of resistance to aphids, such as the resistance to feeding demonstrated in several potato species, including $S$. polyadenium, by J. B. Adams at this research station. Control of aphid populations in such ways as these has the additional effect that it reduces the rate of spread of certain aphid-borne viruses.

The key to the utilization of these 